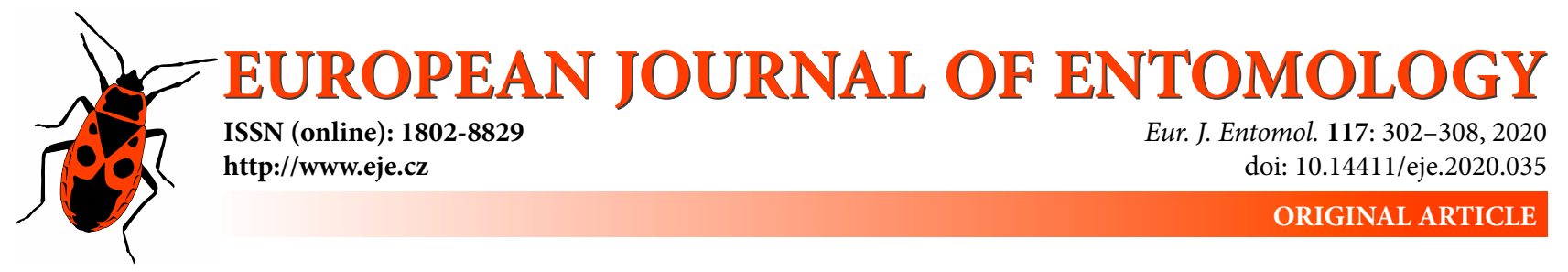

\title{
European database of the life-history, morphological and habitat characteristics of dragonflies (Odonata)
}

\author{
FILIP HARABIŠ and JANA HRONKOVÁ
}

Department of Ecology, Faculty of Environmental Sciences, Czech University of Life Sciences Prague, Kamýcká 129, Prague 6 - Suchdol, CZ-165 00, Czech Republic; e-mails: harabis@fzp.czu.cz, hronkova@fzp.czu.cz

Key words. Odonata, dragonfly, damselfly, freshwater insects, functional ecology, biology, morphology, database, Europe

\begin{abstract}
Climate change and an ever-increasing effect of humans on the great majority of freshwater ecosystems have affected not only individual organisms but also the links between them. In order to effectively protect communities or entire freshwater ecosystems, we need to understand how individual organisms react to these changes and the functional interconnections between individual species. This can be achieved by evaluating the functioning of individual species, i.e. their traits. Dragonflies and damselflies are increasingly used as indicators of changes in freshwater ecosystems. Although this taxonomic group is the subject of many ecological studies, there is no comprehensive database of the traits of European species. This is, why we decided to lay the foundations for an European database of dragonfly traits called dragonfly-database.eu, which is mainly based on Web of Science (WOS) publications and several monographs, and currently includes information on 79 European species. The main advantage of our database is that it is open to downloading, uploading, and storing of data. This is extremely important, because a database's applicability increases with the quality of the data it contains. Initially in compiling the database, we encountered several fundamental shortcomings in the knowledge of some often easily measurable traits in, some species. We believe that in combination with new statistical methods dragonfly-database.eu will become a very useful tool for many ecological studies and more effective conservation of threatened species.
\end{abstract}

\section{INTRODUCTION}

\section{The need to study functional diversity}

There are no doubts that Europe as well as the whole World face an unprecedented decline in insect diversity (Thomas et al., 2004; Potts et al., 2010; Hallmann et al., 2017). A "deadly cocktail" of water pollution, degradation of water habitats, and various phenomena associated with climate change has affected many freshwater ecosystems much more than most terrestrial ecosystems (Sala, 2000; Dudgeon et al., 2006). This trend has been successfully reversed in many countries, but a comprehensive approach is needed for long-term management (Termaat et al., 2015). Eliminating individual negative influences will be difficult, because their effects are strongly correlated and related to various anthropogenic influences (Clausnitzer et al., 2009; Kalkman et al., 2010). In addition, studies on endangered species of dragonfly indicate that the main threats to individual species differ markedly (Dolný et al., 2013; Harabiš \& Dolný, 2015). Many scientists, therefore, are moving away from the idea of protecting individual species and redirecting their efforts to optimizing the management of larger groups of species with similar habitat requirements (Levine, 2015).
Climate change and an ever-increasing effect of humans on the majority of ecosystems affect not only the individual organisms, but also the ecological links between them. The subject of study for many ecological disciplines, therefore, is no longer diversity but "functional diversity" (Levine, 2015). The term "traits" is used to describe basic features of organisms from a functional point of view (Shipley, 2010). In using the term "trait", we refer to features of organisms, which provide an understanding of the interactions between them and their environment (Shipley, 2010). Lack of information about the features of organisms and limited availability of useful analytical tools were the main reasons why functional ecology was not used earlier (Levine, 2015). With the development of comprehensive trait databases over the past several decades, however, the whole field of functional ecology has begun to flourish (Violle et al., 2007).

\section{What are traits?}

Given the wide range of research fields using the term "trait" to describe various things, a clear definition is required, which Violle et al. (2007) provide. A trait can be regarded as any morphological, physiological, behavioural or phenological feature measurable at the individual level, 
from cell to the whole-organism level, without any reference to the environment or any other level of organization. In the field of ecology, the term "functional trait" is increasingly used, but with widely different meanings (Violle et al., 2007). Similarly, ambiguous are the definition and measurement of individual functional traits. The fact that various authors use the same term to represent different features has led several authors to compile a clear manual for the uniform measurement of functional traits for different taxa (Cornelissen et al., 2003; Moretti et al., 2017).

Surprisingly, compared to a wide variety of other aquatic organisms, information on odonates in hydro biological databases is either very basic or completely lacking (Schmidt-Kloiber \& Hering, 2015). To our knowledge, there are currently only two databases summarizing the traits of dragonflies and damselflies: the Morphological and geographical traits of the British Odonata (Powney et al., 2014) and The odonate phenotypic database, a new open data resource for comparative studies on an old insect order (Waller et al., 2019). Unfortunately, the practical use of these databases is severely limited because they are based on just a few sources and contain only the traits of imagoes. Thus, such databases are not comprehensive, and a more complex database is needed.

\section{METHODS}

\section{Database of the traits of European Odonata}

It is not possible to produce a database comparable in range or quality of those currently available for plant traits (Kleyer et al., 2008; Kattge et al., 2011). Fortunately, there are trait databases for groups similar to odonates (dragonflies + damselflies), but we looked not to a database of traits for butterflies or solitary bees, but rather found inspiration in the trait database for European amphibians (Trochet et al., 2014). This might at first seem surprising, but the ecological requirements of odonates are more similar to those of amphibians than of insect pollinators, such as, butterflies. Another very important source of information and inspiration are books that contain information on many traits. The "extraction" of this information is sometimes difficult, because individual (unrelated) values and/or data are often incorporated in these texts, but it can be potentially valuable, because the authors also present data from sources that are difficult to trace and not in internet databases.

We have begun, therefore, to build a completely new database, which currently includes information on the traits of Central European species and in future, hopefully, all species occurring in Europe. This database is primarily based on information in books and scientific articles (WOS, Google Scholar, Scopus). Our goal is to create an open database that will expand with addition of information from new and unpublished studies. We aim to record also valuable information associated with individual traits, including basic information (e.g. number of individuals, temperature, ex situ versus in situ) and variability in the data. It is clear, that average values often do not provide meaningful information about a specific trait. Therefore, our database provides the mean value for a given trait and its variability. For example, the percentage of traits recorded for each species is listed in Table 2.

Any additional information not only increases the accuracy of an estimate, but also maintains its uniqueness. With the increase in use of various advanced meta-analytical tools, the importance of such information will continue to increase.
One of the merits of our database is its comprehensiveness. It is not just the number of traits included that is important, but above all is it summarizes information on all the life stages. This is crucial, because larvae are much more closely associated with particular habitats than the adults, which have considerable ability for dispersal. This is particularly important for conservation biology, for which studies unfortunately only record the ecological requirements of one life stage, typically the imago, and cannot account for why a species or population is struggling (see a critical review of this subject by Stoks \& Córdoba-Aguilar, 2012). Data on larval life histories are relatively rare in published studies, yet we believe that such data exists, but difficult to find in primary sources or is not published. That is why we decided to create an open database with an option for uploading data.

\section{Technical details}

The dragonfly-database.eu provides its users with comprehensive data functions, which enable them to view, export, share and edit data on dragonfly traits. The main data application features a web interface built using such basic web technologies as HTML (HTML5), JavaScript (jQuery framework), and CSS (CSS3). On the web interface (client side), all data are represented by JSON objects. These are dynamically updated by AJAX calls to the server and displayed in a structured table. JSON objects are based on user-selected criteria and are prepared and composed at the server. The back-end (server side) is operated by PHP (PHP 7), which acquires data directly from the MySQL database.

\section{User registration}

There is no requirement to $\log$ in or register in order to view and export data from dragonfly-database.eu. If one intends to upload new data, a new trait, or even a new species, however, that person must register and log in for the purpose of identifying and verifying the data provided. In order to preserve the identity of each record, the record will be identified by "Contributor". The registration form requests a basic user's contact data, such as name and surname, email address and institutional affiliation. User data will be neither provided to third parties nor used for any other purpose. Registered users can view, edit, export and upload data. The administrators of dragonfly-database.eu will be notified about data modifications and verify any changes. Administrators reserve the right to contact the data provider and, in case of doubt about the accuracy of data, to not include it in the database. Only after approval will data become available to all database users.

\section{Data search and export}

A search form allows users to search for data according to taxonomic classification (e.g. family, genus, or species). Therefore, a user needs to specify at least one taxonomic group and information on traits of traits or even one specific trait). Filtered data on odonate traits can be viewed online or exported to a CSV file.

\section{RESULTS}

\section{Content of dragonfly-database.eu}

The current version includes information on 12 morphological, 27 life history, 6 conservation, 8 habitat features for imagoes and 7 morphological and 10 life history features for larvae (total of 70 features, Table 1, Appendix 1) of 79 Central European species. Unfortunately, information on the majority of these features are missing for many species (Table 2).

Generally, the diversity of the Odonata is influenced by historical (geological) and ecological factors. The greatest species diversity occurs in tropical regions. This is prob- 
Table 1A. Summary and short description of the features of the traits included in the database, details of habitat in which species is found and conservation status - imagoes.

\begin{tabular}{|c|c|c|}
\hline Trait & Features & Description \\
\hline \multirow{5}{*}{ Morphological } & Body size & Minimum and maximum body size $[\mathrm{mm}]$ \\
\hline & Abdomen length & Minimum and maximum abdomen length in females and males [mm] \\
\hline & Wingspan & Minimum and maximum wingspan $[\mathrm{mm}]$ \\
\hline & Weight & Minimum, maximum and mean male and female weight [mm] \\
\hline & Coloration & Coloration of female and male body and wings and number of similar species \\
\hline \multirow{18}{*}{ Life history } & Voltinism & The number of generations per year \\
\hline & Overwintering & Overwintering stage - adult, larva, eggs \\
\hline & Flight period & The duration of flight period and main season [months] \\
\hline & Movement and dispersal & Binary variable, do adults routinely migrate \\
\hline & Breeding habitat & Type of habitat dragonflies - Lentic $=$ still water, Lotic $=$ running water \\
\hline & Fecundity & Minimum and maximum number of eggs \\
\hline & Territoriality & Ability to defend territory (binomial data) \\
\hline & Activity & Hunting tactics - sits and waits, or actively looking for food \\
\hline & Courtship & Presence or absence of tandem \\
\hline & Oviposition & Type of substrate in which dragonflies lay eggs (on substrate, exophytic...) \\
\hline & Area & Estimated area of occupancy $(\mathrm{AOO})\left[\mathrm{km}^{2}\right]$ and upper limit $[\mathrm{m}]$ \\
\hline & Sexual maturity & Minimum and Maximum age at sexual maturity [weeks/months] \\
\hline & Emergency & Minimum and maximum time of hatching of $50 \%$ of the population [days] \\
\hline & Pairing & Minimum and maximum time in tandem $[\mathrm{s} / \mathrm{min}]$ \\
\hline & Longevity & Minimum and maximum longevity of adult males/females [days] \\
\hline & Flight height & Minimum and maximum flight height $[\mathrm{cm}]$ \\
\hline & Faunal type & Categorical variable of the faunal type of the species (eurosiberian, afrotropic,...) \\
\hline & Distribution status & Categorical variable that group a species based on its distribution (widespread, local...) \\
\hline \multirow{6}{*}{$\begin{array}{l}\text { Habitat } \\
\text { details }\end{array}$} & Type & This indicates whether the dragonfly lives in this type of habitat (binomial data) \\
\hline & Permanency & Habitat stability 2 categories: temporary, permanent \\
\hline & Substrate & A preferred habitat substrate, 6 categories: muddy, turf, sandy-loamy, sandy, gravel, all of these \\
\hline & Quality & Three categories: dystroph-meso, oligo-eu, meso-eu \\
\hline & Chemistry & Mean, minimum and maximum $\mathrm{pH}$, oxygen and $\mathrm{NH}_{4}[\mathrm{mg} / \mathrm{l}]$ content of water \\
\hline & Shading & Shading: $<30 \%,<50 \%, 50-90 \%$, not shaded \\
\hline \multirow{6}{*}{$\begin{array}{l}\text { Conservation } \\
\text { status }\end{array}$} & JNCC & Species classified using the Red List criteria of Czech Republic \\
\hline & JNCC & Species classified using the Red List criteria of Germany \\
\hline & JNCC & Species classified using the Red List criteria of Poland \\
\hline & JNCC & Species classified using the Red List criteria of Austria \\
\hline & JNCC & Species classified using the national Red List criteria \\
\hline & Population trend & Population development over time: increasing, decreasing, stable \\
\hline
\end{tabular}

ably because a greater diversity of aquatic habitats exist in the tropics and provide a more diverse range of niches. Moreover, if there are some regional refugia, they are mostly still better protected and preserved there than in other areas of the world (Kalkman et al., 2008; Dijkstra et al., 2014). Our database is presently focused on the odonatofauna of Central Europe (79 species, Table 2). Interestingly, the entire Palearctic region is relatively poor in terms of species richness compared to other regions at the same latitude. For example the entire European continent has only a few more species than the state of Texas on the other side of the world (Kalkman et al., 2018). The main causes of this disparity probably include the effect of glaciation in the Pleistocene, when diversity decreased by two thirds and Europe's several geological barriers (Alps and Mediterranean Sea) that limit further expansion of species into central parts of Europe or Asia (Kalkman et al., 2008, 2018).

Table 1B. Summary and short description of the features of the traits included in the database - larvae.

\begin{tabular}{|c|c|c|}
\hline Trait & Features & Description \\
\hline \multirow{4}{*}{ Morphological } & Larval body length & Minimum and maximum body length [mm] \\
\hline & Larval weight & Minimum and maximum larval weight $[\mathrm{mg}]$ \\
\hline & Head width & Minimum and maximum head width of all instars [mm] \\
\hline & Spines & Presence and absence of dorsal and lateral spines \\
\hline \multirow{10}{*}{ Life history } & Embryonic development & Length of embryonic development [weeks] \\
\hline & Temperature & Optimal temperature for larval development \\
\hline & Egg length & Minimum and maximum length of an egg [mm] \\
\hline & Egg width & Minimum and maximum width of an egg [mg] \\
\hline & Number of instars & Number of instars \\
\hline & Larval development & Length of larval development [months] \\
\hline & Day degrees & Dependence of development time on temperature \\
\hline & Sex ratio & Numbers of females and males in specific populations \\
\hline & Defence & Types of defence $-(1)$ passive, (2) dorsal spines, (3) lateral spines \\
\hline & Larval feeding strategy & Uses its - (1) claspers, (2) is a sprawler, (3) burrower, (4) deep burrower, (5) hides \\
\hline
\end{tabular}


Table 2. Percentage of the different features of the traits recorded for each species and its habitat.

\begin{tabular}{|c|c|c|c|c|c|}
\hline Species & Morphological (\%) & $\begin{array}{c}\text { Habitat characteristics } \\
(\%)\end{array}$ & $\begin{array}{l}\text { Dispersal and } \\
\text { territoriality (\%) }\end{array}$ & Reproduction (\%) & Life cycle (\%) \\
\hline Chalcolestes viridis & 57 & 91 & 63 & 100 & 72 \\
\hline Chalcolestes parvidens & 38 & 27 & 38 & 29 & 50 \\
\hline Lestes barbarus & 57 & 55 & 63 & 100 & 67 \\
\hline Lestes dryas & 57 & 64 & 63 & 71 & 72 \\
\hline Lestes macrostigma & 57 & 9 & 63 & 0 & 61 \\
\hline Lestes sponsa & 57 & 91 & 63 & 86 & 78 \\
\hline Lestes virens & 57 & 73 & 63 & 71 & 61 \\
\hline Sympecma fusca & 57 & 91 & 63 & 71 & 61 \\
\hline Sympecma paedisca & 57 & 82 & 63 & 57 & 61 \\
\hline Calopteryx splendens & 67 & 91 & 88 & 71 & 89 \\
\hline Calopteryx virgo & 67 & 91 & 63 & 43 & 67 \\
\hline Platycnemis pennipes & 57 & 100 & 63 & 71 & 67 \\
\hline Enallgma cyathigerum & 38 & 91 & 63 & 71 & 78 \\
\hline Coenagrion hastulatum & 38 & 82 & 63 & 71 & 78 \\
\hline Coenagrion lunulatum & 38 & 82 & 63 & 43 & 72 \\
\hline Coenagrion mercuriale & 38 & 91 & 38 & 43 & 78 \\
\hline Coenagrion ornatum & 38 & 82 & 75 & 14 & 61 \\
\hline Coenagrion puella & 38 & 91 & 63 & 71 & 83 \\
\hline Coenagrion pulchellum & 38 & 91 & 75 & 43 & 61 \\
\hline Coenagrion scitulum & 38 & 55 & 75 & 14 & 61 \\
\hline Ischnura elegans & 38 & 91 & 63 & 71 & 78 \\
\hline Ischnura pumilio & 38 & 91 & 75 & 71 & 72 \\
\hline Erythromma lindenii & 38 & 91 & 63 & 43 & 61 \\
\hline Erythromma najas & 38 & 91 & 63 & 43 & 61 \\
\hline Erythromma viridulum & 38 & 73 & 88 & 43 & 61 \\
\hline Nehalennia speciosa & 38 & 91 & 88 & 71 & 72 \\
\hline Pyrrhosoma nymphula & 38 & 91 & 63 & 100 & 89 \\
\hline Ceriagrion tenellum & 38 & 82 & 50 & 29 & 83 \\
\hline Brachytron pratense & 48 & 91 & 100 & 43 & 61 \\
\hline Anaciaeschna isoceles & 67 & 64 & 88 & 29 & 61 \\
\hline Anax ephippiger & 19 & 45 & 63 & 43 & 33 \\
\hline Anax imperator & 48 & 82 & 88 & 57 & 67 \\
\hline Anax parthenope & 48 & 64 & 88 & 43 & 61 \\
\hline Aeshna affinis & 52 & 73 & 63 & 43 & 67 \\
\hline Aeshna caerulea & 52 & 82 & 63 & 29 & 61 \\
\hline Aeshna cyanea & 67 & 91 & 75 & 57 & 72 \\
\hline Aeshna grandis & 48 & 55 & 63 & 43 & 61 \\
\hline Aeshna juncea & 48 & 82 & 63 & 29 & 61 \\
\hline Aeshna mixta & 48 & 82 & 63 & 43 & 61 \\
\hline Aeshna viridis & 57 & 45 & 25 & 0 & 61 \\
\hline Aeshna subarctica & 38 & 82 & 63 & 43 & 61 \\
\hline Stylurus flavipes & 57 & 45 & 100 & 100 & 72 \\
\hline Gomphus pulchellus & 57 & 82 & 50 & 14 & 78 \\
\hline Gomphus vulgatissimus & 57 & 91 & 88 & 71 & 72 \\
\hline Ophiogompus cecilia & 57 & 82 & 63 & 57 & 72 \\
\hline Onychogomphus forcipatus & 57 & 91 & 88 & 43 & 61 \\
\hline Cordulegaster bidentata & 48 & 91 & 88 & 57 & 61 \\
\hline Cordulegaster boltonii & 48 & 91 & 88 & 14 & 61 \\
\hline Corddulegaster heros & 48 & 55 & 50 & 14 & 61 \\
\hline Cordulia aenea & 57 & 73 & 88 & 71 & 67 \\
\hline Somatochlora alpestris & 57 & 82 & 63 & 100 & 89 \\
\hline Somatocholra arctica & 57 & 82 & 88 & 71 & 72 \\
\hline Somatochlora flavomaculata & 57 & 82 & 88 & 71 & 72 \\
\hline Somatochlora metallica & 57 & 73 & 88 & 57 & 72 \\
\hline Somatochlora meridionale & 57 & 27 & 50 & 14 & 61 \\
\hline Epitheca bimaculata & 57 & 64 & 88 & 71 & 72 \\
\hline Oxygastra curtisii & 38 & 45 & 50 & 0 & 33 \\
\hline Leucorrhinia albifrons & 38 & 82 & 63 & 100 & 72 \\
\hline Leucorrhinia caudalis & 38 & 91 & 75 & 43 & 61 \\
\hline Leucorrhinia dubia & 38 & 82 & 63 & 71 & 83 \\
\hline Leucorrhinia pectoralis & 38 & 91 & 63 & 57 & 67 \\
\hline Leucorrhinia rubicunda & 48 & 82 & 63 & 14 & 61 \\
\hline Libellula depressa & 38 & 91 & 88 & 43 & 61 \\
\hline Libellula fulva & 38 & 91 & 63 & 100 & 61 \\
\hline Libellula quadrimaculata & 38 & 91 & 88 & 71 & 72 \\
\hline Orthetrum albistylum & 38 & 73 & 63 & 43 & 61 \\
\hline Orthetrum brunneum & 38 & 91 & 63 & 71 & 61 \\
\hline Orthetrum cancellatum & 43 & 91 & 88 & 71 & 83 \\
\hline Orthetrum coerulescens & 43 & 91 & 63 & 57 & 67 \\
\hline Crocothemis erythraea & 38 & 82 & 88 & 86 & 61 \\
\hline Sympetrum danae & 38 & 91 & 63 & 71 & 61 \\
\hline Sympetrum depressiusculum & 38 & 82 & 63 & 57 & 61 \\
\hline Sympetrum flaveolum & 38 & 73 & 63 & 57 & 61 \\
\hline Sympetrum fonscolombii & 38 & 82 & 63 & 43 & 61 \\
\hline Sympetrum meridionale & 38 & 55 & 63 & 14 & 61 \\
\hline Sympetrum pedemontanum & 38 & 82 & 63 & 43 & 67 \\
\hline Sympetrum sanguineum & 38 & 91 & 63 & 57 & 67 \\
\hline Sympetrum striolatum & 43 & 91 & 63 & 71 & 67 \\
\hline Sympetrum vulgatum & 38 & 91 & 63 & 43 & 67 \\
\hline
\end{tabular}




\section{DISCUSSION}

\section{The invaluable value of ordinary data}

In initially compiling the database, we realized that many authors not only do not publish their raw data or even provide essential information necessary for the interpretation of their results. To our surprise, we were unable to find basic information on the numbers of individuals upon which a given value of a morphological feature is based. Especially the authors of books, often take information from other sources quite uncritically or do not mention the source of the information. Many of the values cited for basic morphological features are from other sources, for example it was not possible to trace whether these values (or range of values) are based on the measurement of 1000 , 50 or even just 5 individuals. Also often unstated is which dimension is considered when measuring the length of a wing, or whether the values are for individuals from Central Europe, Asia, or elsewhere.

We are increasingly confronted with new indices, methods of estimation and measurements and definitions for individual traits. Meanwhile, we continue to struggle with the fact, that basic morphological features are not yet clearly defined, or standardized. A first and truly fundamental step was taken recently in the form a handbook on the protocols for measuring such features by Moretti et al. (2017). Here, they clearly define a broad scale of features and standardized procedures for sampling them, which should be one of the first steps in organized sampling for collecting data. However, there remains the problem of the motivation for providing such data. Authors simply do not realize that information on individual features has little value, but by combining it with other information to create a larger whole, greatly increases its value. For the resolution of many ecological issues we need large amounts of data or measurements. Often, it is very time consuming, if not impossible, to obtain such datasets. Many authors try to include as little information as possible in their publications and provide only the results of statistical tests or some basic plots. To some extent, this behaviour forces us to quote only the conclusions of studies without any knowledge of the primary data. We understand that scientists do so in good faith and the expectation that their data will be of use to others. Unfortunately, such behaviour does not contribute much to the general knowledge about a given problem.

Another difficulty we encountered is a critical lack of information on some species while, conversely, some other species have in the past received considerable attention. This is mainly because authors tend to choose species that are easy to rear in the laboratory. For example, the damselfly species Lestes sponsa and Ischnura elegans are typical examples of such species in having relatively short life cycles and being relatively easily reared in a laboratory. For that reason, we have a lot of information about these species. On the other hand, there are many common species, such as Orthetrum cancellatum, which has not received such attention, in which case our database only includes very general information on the morphological variability, phylogeny and ecological requirements of this species.

\section{New methods $=$ new opportunities}

We have already mentioned meta-analytical methods, which many scientists perceive to be very powerful tools for solving very complex issues (Gurevitch et al., 2018). The greatest weakness of these methods lies in the fact that, however, sophisticated the statistical methods they are very dependent on the quality of the data (Koricheva \& Gurevitch, 2014). Also very promising is the use of traits as one of the explanatory "blocks" of variables in modelbased approaches for analysing community data (Warton et al., 2015; Ovaskainen et al., 2017). None of these methods, however, can substitute for deficiencies in primary data. Therefore, we intend to continue collecting data in order to enhance the information on morphological variability and life history traits of individual species.

Another aim is to include in the database other species of dragonflies and damselflies occurring in other regions of Europe. We greatly appreciate those studies on the differences in life history traits of individual species like those of De Block \& Stoks (2004), De Block et al. (2008) and Schiel \& Buchwald (2015a, b). We believe that more of these complex studies will help us to better understand such understudied phenomena as carry-over effects (Stoks \& Córdoba-Aguilar, 2012). Clearly much remains to be done to improve our understanding of European odonate species and their ecology. We believe dragonfly-database. eu can be an important step in that direction by improving the availability of information. We are very thankful to our colleagues within this field for their support of this endeavour and look forward to receiving further data.

ACKNOWLEDGEMENTS. We are grateful to M. Bartoušek for programming the web site. This study formed part of project GAČR 18-244255 that was funded by the Czech Science Foundation and IGA 20174213 of the Czech University of Life Sciences Prague.

\section{REFERENCES}

Clausnitzer V., Kalkman V.J., Ram M., Collen B., Baillie J.E.M., Bedjanič M., Darwall W.R.T.T., Dijkstra K.-D.D.B., Dow R., Hawking J. ET AL. 2009: Odonata enter the biodiversity crisis debate: The first global assessment of an insect group. Biol. Conserv. 142: 1864-1869.

Cornelissen J.H.C., Lavorel S., Garnier E., Díaz S., Buchmann N., Gurvich D.E., Reich P.B., ter Steege H., Morgan H.D., Heijden van der M.G.A., Pausas J.G. \& Poorter H. 2003: A handbook of protocols for standardised and easy measurements of plant functional traits worldwide. - Aust. J. Bot. 51: 335-380.

De Block M. \& Stoks R. 2004: Life-history variation in relation to time constraints in a damselfly. - Oecologia 140: 68-75.

De Block M., McPeek M.A. \& Stoks R. 2008: Life-history evolution when Lestes damselflies invaded vernal ponds. - Evolution 62: 485-493.

Dijkstra K.-D.B., Monaghan M.T. \& Pauls S.U. 2014: Freshwater biodiversity and aquatic insect diversification. - Annu. Rev. Entomol. 59: 143-163. 
DolnÝ A., MižıČová H. \& HARABIŠ F. 2013: Natal philopatry in four European species of dragonflies (Odonata: Sympetrinae) and possible implications for conservation management. $-J$. Insect Conserv. 17: 821-829.

Dudgeon D., Arthington A.H., Gessner M.O., Kawabata Z.-I., Knowler D.J., LÉVÊque C., Naiman R.J., Prieur-Richard A.H., Soto D., Stiassny M.L.J. \& Sullivan C.A. 2006: Freshwater biodiversity: importance, threats, status and conservation challenges. - Biol. Rev. (Cambridge) 81: 163-182.

Gurevitch J., Koricheva J., Nakagawa S. \& Stewart G. 2018: Meta-analysis and the science of research synthesis. - Nature 555: $175-182$.

Hallmann C.A., Sorg M., Jongejans E., Siepel H., Hofland N., Schwan H., Stenmans W., Müller A., Sumser H., Hörren T., Goulson D. \& De Kroon H. 2017: More than 75 percent decline over 27 years in total flying insect biomass in protected areas. - PLoS ONE 12(10): e185809, 21 pp.

Harabiš F. \& DolNÝ A. 2015: Necessity for the conservation of drainage systems as last refugia for threatened damselfly species, Coenagrion ornatum. - Insect Conserv. Divers. 8: 143151.

Kalkman V.J., Clausnitzer V., Dijkstra K.-D.B., OrR A.G., PAULSON D.R. \& VAN Tol J. 2008: Global diversity of dragonflies (Odonata) in freshwater. - Hydrobiologia 595: 351-363.

Kalkman V.J., Boudot J.-P., Bernard R., Conze K.-J., De KniJf G., Dyatlova E., Ferreira S., Jovic M., Ott J., Riservato E. \& SAHLÉn G. 2010: European Red List of Dragonflies. Publications Office of the European Union, Luxembourg, $38 \mathrm{pp}$.

Kalkman V.J., Boudot J.-P., Bernard R., De KniJf G., Suhling F. \& TermaAt T. 2018: Diversity and conservation of European dragonflies and damselflies (Odonata). - Hydrobiologia 811: 269-282.

Kattge J., Díaz S., Lavorel S., Prentice I.C., Leadley P., Bönisch G., Garnier E., Westoby M., Reich P.B., Wright I.J. ET AL. 2011: TRY - a global database of plant traits. - Glob. Chang. Biol. 17: 2905-2935.

Kleyer M., BekKer R.M., Knevel I.C., Bakker J.P., Thompson K., Sonnenschein M., Poschlod P., Van Groenendael J.M., KuimeŠ L., KuimeŠovÁ J. ET AL. 2008: The LEDA traitbase: A database of life-history traits of the Northwest European flora. - J. Ecol. 96: 1266-1274.

Koricheva J. \& Gurevitch J. 2014: Uses and misuses of metaanalysis in plant ecology. - J. Ecol. 102: 828-844.

LeVINE J.M. 2015: A trail map for trait-based studies. - Nature 529: 163-164.

Moretti M., Dias A.T.C., de Bello F., Altermatt F., Chown S.L., azcárate F.M., Bell J.R., Fournier B., Hedde M., Hortal J. ET AL. 2017: Handbook of protocols for standardized measurement of terrestrial invertebrate functional traits. - Funct. Ecol. 31: $558-567$.
Ovaskainen O., Tikhonov G., Norberg A., Guillaume Blanchet F., Duan L., Dunson D., Roslin T. \& Abrego N. 2017: How to make more out of community data? A conceptual framework and its implementation as models and software. - Ecol. Lett. 20: $561-576$.

Potts S.G., Biesmeijer J.C., Kremen C., Neumann P., Schweiger O. \& KunIN W.E. 2010: Global pollinator declines: Trends, impacts and drivers. - Trends Ecol. Evol. 25: 345-353.

Powney G.D., BRooks S.J., Barwell L.J., Bowles P., FitT R.N.L., Pavitt A., Spriggs R.A \& IsaAc N.J.B. 2014: Morphological and geographical traits of the British Odonata. - Biodivers. Data J. 2: e1041, 12 pp.

SALA O.E. 2000: Global biodiversity scenarios for the year 2100 . - Science 287: 1770-1774.

Schiel F.J. \& Buchwald R. 2015a: Hatching phenology of Odonata species inhabiting temporary and permanent water bodies (Odonata: Lestidae, Aeshnidae, Libellulidae). — Int. J. Odonatol. 18: 105-123.

Schiel F.J. \& Buchwald R. 2015b: Contrasting life-history patterns between vernal pond specialists and hydroperiod generalists in Lestes damselflies (Odonata: Lestidae). - Odonatologica 44: 349-374.

SchmidT-Kloiber A. \& Hering D. 2015: Www.freshwaterecology.info - An online tool that unifies, standardises and codifies more than 20,000 European freshwater organisms and their ecological preferences. - Ecol. Indic. 53: 271-282.

ShIPley B. 2010: From Plant Traits to Vegetation Structure. Cambridge University Press, Cambridge, $277 \mathrm{pp}$.

Stoks R. \& Córdoba-Aguilar A. 2012: Evolutionary ecology of Odonata: A complex life cycle perspective. - Annu. Rev. Entomol. 57: 249-265.

Termaat T., van Grunsven R.H.A., Plate C.L. \& van Strien A.J. 2015: Strong recovery of dragonflies in recent decades in The Netherlands. - Freshw. Sci. 34: 1094-1104.

Thomas J.A., Telfer M.G., Roy D.B., Preston C.D., Greenwood J.J.D., Asher J., Fox R., Clarke R.T. \& Lawton J.H. 2004: Comparative losses of British butterflies, birds, and plants and the global extinction crisis. - Science 303: 1879-1881.

Trochet A., Moulherat S., Calvez O., Stevens V.M., Clobert J. \& SCHMELLER D.S. 2014: A database of life-history traits of European amphibians. - Biodivers. Data J. 2: e4123, 38 pp.

Violle C., Navas M., Vile D., Kazakou E. \& Fortunel C. 2007: Let the concept of trait be functional! - Oikos 116: 882-892.

Waller J.T., Willink B., Tschol M. \& Svensson E.I. 2019: The odonate phenotypic database, a new open data resource for comparative studies of an old insect order. - Sci. Data 6: 316, $6 \mathrm{pp}$.

Warton D.I., Shipley B., Hastie T. \& O'Hara R.B. 2015: CATS regression - a model-based approach to studying trait-based community assembly. — Methods Ecol. Evol. 6: 389-398.

Received October 30, 2019; revised and accepted June 11, 2020 Published online July 14, 2020 


\section{Adults}
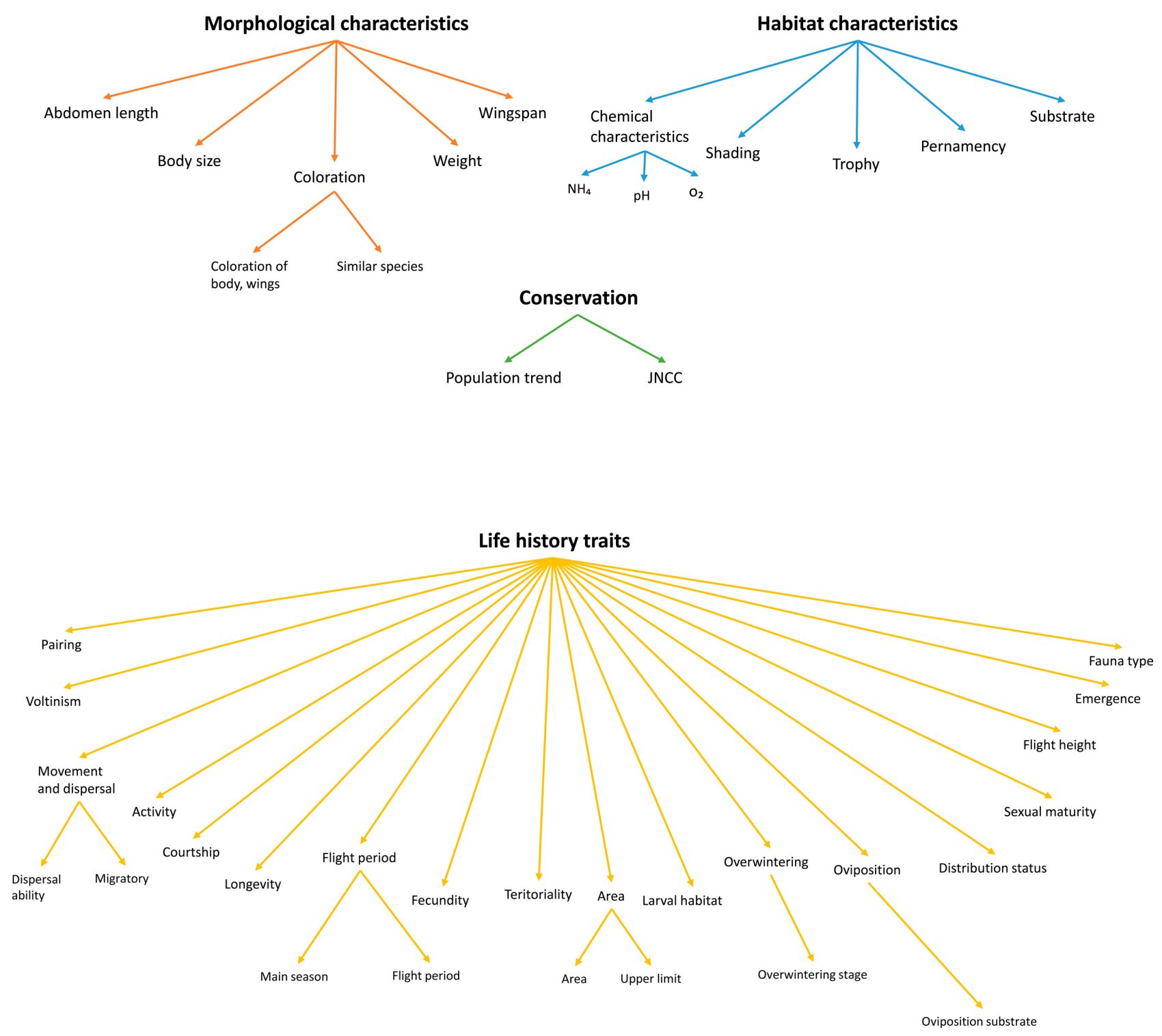

\section{Larvae}
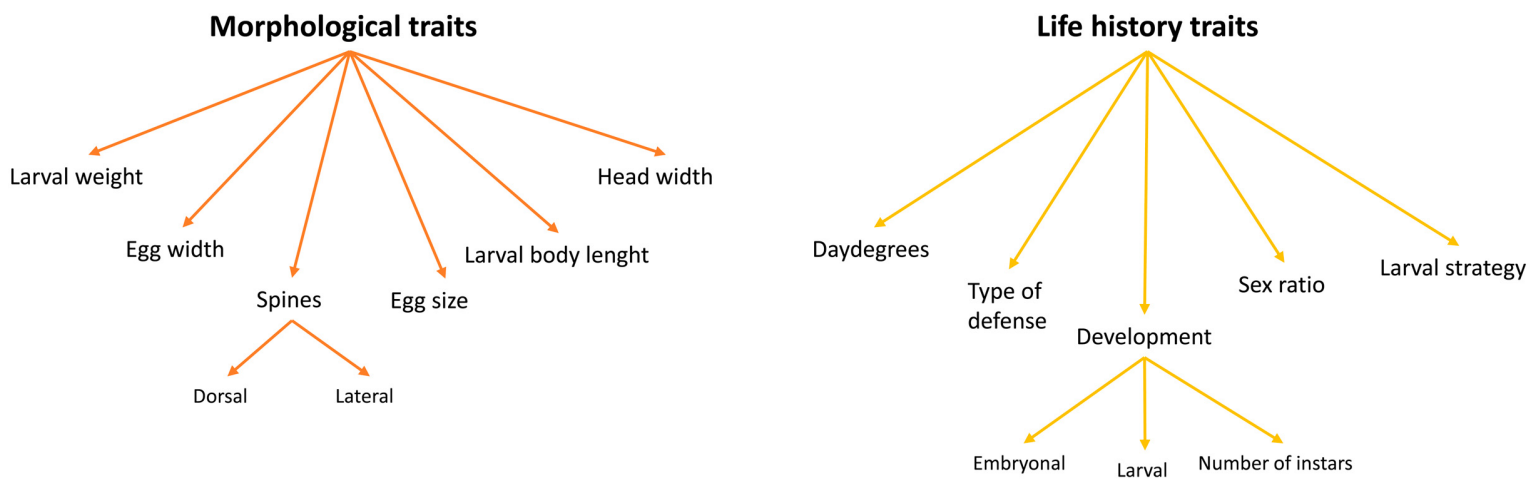

Appendix 1. Features of all the traits included in the database. 